\title{
Fail Forward: Students' Mistakes as Teachable Moments
}

\author{
Cusrow J. Dubash ${ }^{1, *}$, Rimesha Farooq ${ }^{2}$ \\ ${ }^{1}$ Lampro Mellon IT Solutions, Lahore 54000, Pakistan \\ ${ }^{2}$ Department of Education, Forman Christian College, Lahore 54600, Pakistan
}

Received January 22, 2021; Revised March 2, 2021; Accepted March 23, 2021

\section{Cite This Paper in the following Citation Styles}

(a): [1] Cusrow J. Dubash, Rimesha Farooq, "Fail Forward: Students' Mistakes as Teachable Moments," Universal Journal of Educational Research, Vol. 9, No. 4, pp. 856 - 861, 2021. DOI: 10.13189/ujer.2021.090419.

(b): Cusrow J. Dubash, Rimesha Farooq (2021). Fail Forward: Students' Mistakes as Teachable Moments. Universal Journal of Educational Research, 9(4), 856 - 861. DOI: 10.13189/ujer.2021.090419.

Copyright $\bigcirc 2021$ by authors, all rights reserved. Authors agree that this article remains permanently open access under the terms of the Creative Commons Attribution License 4.0 International License

\begin{abstract}
This study was undertaken in five public sector and five private sector universities in Lahore, Pakistan. One hundred students from each institution were randomly identified and asked to write an essay at the start of semester 1 and end of semester 8. All essays were analyzed for errors. All errors were then categorized into eleven general types for each round. The results showed no major change from semester 1 to semester 8 in the number of errors made. Also, not much variation was evident between the public sector and private sector universities. This indicates that the remedial English courses designed by the institutions were not helping the students improve. These were either too general or were taught with no specific purpose in mind. The universities should look into the eleven broad categories in which most of the students' errors fall in order to design remedial English courses that are meaningful and benefit students. Errors and mistakes made by students should be treated as learning opportunities for students with plenty of practice work. It is high time universities look at their course offerings with an open mind and the student as the prime beneficiary of their work.
\end{abstract}

Keywords Errors, Remedial English, Learning from Mistakes, Categories of Errors

\section{Introduction}

In many parts of the world, English is taught as a second or third language. Students face great difficulties in learning this new language as there is no feedback or help from home and the only feedback from the teacher is in the form of mistake identification. In many cases, the written work returned to the student after evaluation is more red than blue, black or penciled. The teacher has painstakingly corrected all the students' mistakes and this leads to no learning. Unless the students correct their own errors, they are not learning. The benefit of the teachers' exercise in correcting students' work is futile as it does not benefit the students. The teachers' job should be to identify the errors and then have the students fix them. Then learning from mistakes will happen. Mistakes are teachable moments, opportunities to learn and NOT chances to punish the students for not learning correctly.

Academia in countries where English is a second language, faces the issue of bilingual mode of education. Degree awarding institutions are conscious of the fact that their students have to compete in the job market so they must be trained and ready for easy employment. Command on English language has become inevitable to secure a promising job; the medium of instruction has swiftly altered from the native language to English. Many private language institutions have mushroomed just to teach students and make them fluent in English. Special courses are offered to develop the basic understanding of English language; even teachers themselves have to do English proficiency courses. However, besides the ever-increasing efforts, the students' grip on English language is not commendable.

Students are expected to be apt in their English speaking and writing skills, but unfortunately the situation is contrary to what is anticipated. Students lack clear 
concepts of English language which conspicuously is reflected in their writing. Today when English medium instruction is the norm, students are instructed to communicate in English and the administration makes it compulsory for teachers to deliver their lectures in English yet the results are rather disappointing. Students still find writing in English to be a daunting task. The written expression in English is anything but immaculate; the point to ponder over is why after earnest efforts, learning and using English is beyond the capacity of students. This research paper aims to highlight the repetitive pattern of errors where students make in their comprehension of English language. This study is based on research conducted in academic institutions, mistakes made have been categorized so that areas where students face most complexities can be identified and matching help provided.

Attempts to analyze errors in English have a wide scope but it skips the minute details. Research studies conducted earlier, lay focus on the general errors. Solutions suggested previously are regarding the same issues due to which not only do the problems still exist but no progress is taking place as well.

Lessia Kotsyuk [3] in her article, "English Language Error Analysis of the Written Texts Produced by Ukrainian Learners: Data Collection", has discussed the issues in understanding English language in a very broad way. The article, however, does not elaborate on how actually the data were collected. The problems which the author has mentioned do not cover all aspects of the topic. Finally the author provides strategies for teachers to improve their teaching methods.

Sharma and Tripathi [10] in their article: Error Analysis for English Language Teaching at Primary Level", explains the techniques through which teachers can make their students learn English language in a more accurate manner. The article actually emphasizes on the significance of ELT and how it should be made more systematic.

The article, "Error Analysis and Second Language Acquisition" by Ali Akbar Khan [2], is an attempt to discuss the difficulties that English teachers face while teaching English as a second language. The author has accurately mentioned that repetition of errors outshines the efforts of academia but does not elucidate that these errors are based on his observations or some case studies. It is not clear what has been the source of the information and how it was collected.

Diana Presada and Mihaela Badea [7] in their article, "The Effectiveness of Error Analysis in Translation classes", explicate the significance of error analysis in the context of translation studies. Error analysis is indeed crucial where English is the second language but the question still remains that how errors can be categorized or identified.

Nada Salih A. Ridha [9] in "The Effect of EFL
Learners' Mother Tongue on Their Writing in English: An Error Study", discusses the theoretical aspects of error analysis. The author has very minutely expounded what error analysis means and what are its various categories.

In "Error Analysis: Beyond the Basic Writer", Barbara Bennett Schillinger [11], elaborates on what is the significance of error analysis for the teachers. How it can be used to make students learn about their mistakes and not repeat them.

Maureen Mulligan [6] in her article, "Error Analysis of Written and Spoken English: Practical Suggestions", brings forward how the repetitive errors in English speaking and writing can be overcome. The author's main interest lies in how we should device various strategies by which students can be confident that they can speak and write in English flawlessly.

In "Error Analysis: A Case Study on Non-Native English Speaking College Applicants' Electronic Mail Communications", Casey Kraichoke [4], talks about the theoretical aspects of error analysis.

In light of the above and many other research studies and articles, it is obvious that the majority emphasize on the theoretical aspects of English error analysis. Many authors are more interested in highlighting the pedagogical side of error analysis. This research paper emphasizes on identifying errors which students make and classifying them into broad categories. This would help institutions tailor their remedial English courses to help students overcome these common error categories and avoid them in their future writings. Errors that students make should help them learn from them.

\section{Methodology}

The population for the study was the semester 1 freshmen students in public and private sector universities in Lahore. Five public and five private sector universities were selected at random. From each of the ten universities one hundred freshmen students enrolled in semester, one course was randomly chosen to be the sample of the study. The total sample size was therefore 1000 students.

The sample was tested in semester 1 and then again the same sample was tested in semester 8 . Both tests were diagnostic to see the type of mistakes students make while writing in English. The sample included roughly 50\% males and 50\% females. However, the study did not look at how the males or females performed. The entire sample was considered as a single group.

Each student had to write a twelve-hundred-word essay on a given topic in 45 minutes during each testing time in semester 1 and semester 8 . To account for attrition and any dropouts, in semester 1120 students were put through the writing activity and in semester 8 the ones still there were required to right the essay. This way we had the same 100 students from each university for both sittings. 
No university showed less than a hundred students sitting for the semester 8 round. Some had a few more which were ignored. The topics were different for the two semesters. The tests were conducted at each university campus in familiar settings for the students. The essays submitted were then copied and assessed by three experts independently.

Each essay was then reviewed by the three experts collectively. The errors marked by each expert were collated. If at least two experts had marked the same error it went into the error pool. The errors in the error pool were categorized and placed in one of eleven categories as agreed by the three experts. Average mistakes per type of error were calculated. Average overall mistakes per institution were also calculated.

\section{Results}

The categorization of errors was as follows:

1. Punctuation: Quite messed up across the board; most common were commas, the use of colons and semicolons, and apostrophes.

2. Tenses: Common errors were starting a sentence in one tense and completing it with a different tense; using correct forms of the verbs in the respective tenses.

3. Agreement: Noun - verb agreement in sentences; singular and plural agreement; and start and finish tenses in sentences.

4. Objective Case: The correct use of who and whom was a recurrent error.

5. Cases of Mistaken Identity: Not sure of what belongs where in a sentence; identity messed up.

6. Cutting down the Extras: Stems from the notion that 'more is better'; this leads to repetition of words and phrases or the use of double negatives.

7. Supplying the Missing Links: Most often seen as the absence of transition words or obvious missing of connectors.

8. Tossing out the Odds and Ends: Trying to meet the word count by saying the same thing again and again using a different combination of words.

9. Adverbs and Adjectives: Mixing the two parts of speech as if one substitutes the other.

10. Putting Words in Their Places: Dangling modifiers that make no sense of the sentence.

11. Words Liable to be Confused: These deal with homonyms, heteronyms and other easily confused words; spellings matter.

Table 1. Number of errors identified per university per category

\begin{tabular}{|c|c|c|c|c|c|c|c|c|c|c|c|c|}
\hline \multicolumn{2}{|r|}{ Category of Error } & \multirow[t]{2}{*}{ Testing } & \multicolumn{5}{|c|}{ Public Universities } & \multicolumn{5}{|c|}{ Private Universities } \\
\hline & & & 1 & 2 & 3 & 4 & 5 & 1 & 2 & 3 & 4 & 5 \\
\hline & Punctuation & Semester 1 & 90 & 81 & 91 & 86 & 79 & 100 & 92 & 81 & 91 & 85 \\
\hline & & Semester 8 & 90 & 82 & 90 & 84 & 79 & 98 & 92 & 80 & 90 & 80 \\
\hline \multirow[t]{2}{*}{2.} & Tenses & Semester 1 & 90 & 88 & 81 & 84 & 85 & 92 & 92 & 89 & 88 & 89 \\
\hline & & Semester 8 & 86 & 87 & 81 & 85 & 84 & 90 & 91 & 86 & 87 & 89 \\
\hline \multirow[t]{2}{*}{3.} & Agreement & Semester 1 & 85 & 88 & 91 & 81 & 81 & 94 & 90 & 94 & 99 & 88 \\
\hline & & Semester 8 & 83 & 89 & 90 & 82 & 80 & 93 & 88 & 93 & 96 & 85 \\
\hline \multirow[t]{2}{*}{4.} & Objective Case & Semester 1 & 75 & 74 & 81 & 79 & 80 & 84 & 81 & 81 & 84 & 76 \\
\hline & & Semester 8 & 77 & 74 & 80 & 78 & 79 & 82 & 80 & 79 & 83 & 75 \\
\hline & Cases of Mistaken Identity & Semester 1 & 74 & 79 & 80 & 74 & 79 & 81 & 83 & 88 & 88 & 88 \\
\hline & & Semester 8 & 73 & 77 & 77 & 74 & 78 & 78 & 81 & 88 & 89 & 86 \\
\hline & Cutting Down the Extras & Semester 1 & 71 & 84 & 76 & 74 & 74 & 83 & 84 & 79 & 77 & 81 \\
\hline & & Semester 8 & 73 & 83 & 75 & 79 & 73 & 81 & 81 & 81 & 81 & 81 \\
\hline \multirow[t]{2}{*}{7.} & Supplying the Missing Links & Semester 1 & 80 & 83 & 88 & 84 & 89 & 91 & 84 & 93 & 85 & 87 \\
\hline & & Semester 8 & 79 & 82 & 85 & 80 & 83 & 88 & 81 & 90 & 84 & 83 \\
\hline \multirow[t]{2}{*}{8.} & Tossing Out the Odds and Ends & Semester 1 & 71 & 72 & 73 & 81 & 87 & 81 & 81 & 88 & 84 & 83 \\
\hline & & Semester 8 & 70 & 74 & 73 & 82 & 85 & 80 & 80 & 86 & 85 & 84 \\
\hline \multirow[t]{2}{*}{9.} & Adverbs and Adjectives & Semester 1 & 90 & 93 & 84 & 87 & 85 & 85 & 87 & 91 & 88 & 89 \\
\hline & & Semester 8 & 88 & 90 & 83 & 86 & 86 & 86 & 85 & 93 & 89 & 87 \\
\hline \multirow[t]{2}{*}{10.} & Putting Words in Their Places & Semester 1 & 73 & 79 & 76 & 78 & 77 & 81 & 79 & 80 & 79 & 79 \\
\hline & & Semester 8 & 75 & 81 & 75 & 76 & 76 & 80 & 80 & 80 & 78 & 78 \\
\hline & Words Liable to be Confused & Semester 1 & 81 & 85 & 91 & 90 & 89 & 89 & 88 & 87 & 88 & 85 \\
\hline & & Semester 8 & 81 & 84 & 90 & 90 & 90 & 87 & 85 & 86 & 88 & 84 \\
\hline & Mean / Average Individual & Semester 1 & 80 & 82 & 83 & 82 & 82 & 87 & 86 & 86 & 86 & 84 \\
\hline & Mean / Average Individual & Semester 8 & 80 & 82 & 82 & 82 & 81 & 86 & 84 & 86 & 86 & 83 \\
\hline & Mean / Average Groups & Semester 1 & \multicolumn{5}{|c|}{82} & \multicolumn{5}{|c|}{86} \\
\hline & Mean / Average Groups & Semester 8 & \multicolumn{5}{|c|}{81} & \multicolumn{5}{|c|}{85} \\
\hline
\end{tabular}


Table 2. Comparison of errors identified in semesters 1 and 8

\begin{tabular}{|c|c|c|c|c|c|c|c|c|c|}
\hline & \multicolumn{4}{|c|}{ Public } & \multicolumn{4}{|c|}{ Private } \\
\hline & & \multicolumn{2}{|c|}{ Semester 1} & \multicolumn{2}{|c|}{ Semester 8} & \multicolumn{2}{|c|}{ Semester 1} & \multicolumn{2}{|c|}{ Semester 8} \\
\hline & & Total & Mean & Total & Mean & Total & Mean & Total & Mean \\
\hline & Punctuation & 427 & 85 & 425 & 85 & 449 & 90 & 440 & 88 \\
\hline 2. & Tenses & 428 & 86 & 423 & 85 & 450 & 90 & 443 & 89 \\
\hline 3. & Agreement & 426 & 85 & 424 & 85 & 465 & 93 & 455 & 91 \\
\hline 4. & Objective Case & 389 & 78 & 388 & 78 & 406 & 81 & 399 & 80 \\
\hline 5. & Cases of Mistaken Identity & 386 & 77 & 379 & 76 & 428 & 86 & 422 & 84 \\
\hline 6. & Cutting Down the Extras & 379 & 76 & 383 & 77 & 404 & 81 & 405 & 81 \\
\hline 7. & Supplying the Missing Links & 424 & 85 & 409 & 82 & 440 & 88 & 426 & 85 \\
\hline 8. & Tossing Out the Odds and Ends & 384 & 77 & 384 & 77 & 417 & 83 & 415 & 83 \\
\hline 9. & Adverbs and Adjectives & 439 & 88 & 433 & 87 & 440 & 88 & 440 & 88 \\
\hline 10. & Putting Words in Their Places & 383 & 77 & 383 & 77 & 398 & 80 & 396 & 79 \\
\hline & Words Liable to be Confused & 436 & 87 & 435 & 87 & 437 & 87 & 430 & 86 \\
\hline & Average & \multicolumn{2}{|c|}{82} & \multicolumn{2}{|c|}{81} & \multicolumn{2}{|c|}{86} & \multicolumn{2}{|c|}{85} \\
\hline
\end{tabular}

In table 1, the number of errors in each category for each university was collated. The number of overall errors in each category was also collated. Table 1 gives the summary of all errors for all ten universities for the testing in semester 1 and semester 8 . It also shows the average of errors for each university as well as average for the public or private sector cluster.

In table 2, the number of errors may seem to be high that is because each time a student made that error even in the same essay and it was counted individually. So if a student made errors with placing a comma five times in the essay, it was counted as five errors not just one.

\section{Discussion}

Total eleven categories of commonly made errors by the students of public and private universities were identified. The experts through the essays written by the students identified those errors. The errors made by students in their first semester and then in the eighth semester were recorded and exhibited in Tables 1 and 2.

According to the data, the average number of errors committed from the defined eleven error categories by the students studying at Private universities was slightly more compared to the average errors committed by the public universities students. The students of both Private and Public Universities showed no significant improvement in error making in the eighth semester. The most common errors made by the students at the public universities were mixing of adverbs and adjectives and on the other hand, the private universities' students made noun-verb and singular-plural agreement errors. Students at the public universities did not show any progress in preventing the errors in the category of punctuation, objective case, agreement and tossing out the odds and ends, putting the words in their places and liable words to be confused. A little improvement was noted in the category of tenses, cases of mistaken identity, cutting down the extras, supplying the missing links and adverbs and adjectives.

Private universities students showed negligible improvement in making the errors in the category of punctuation, tenses, agreement, objective cases, cases of mistaken identity, supplying the missing links, putting the words in their places and words liable to be confused. No improvement was observed in the category of adverbs and adjectives and tossing out the odds and ends. The numbers of errors were less in the eighth semester as compared to the errors committed in the first semester.

According to Wolff [13], English is not a foreign language anymore but is a qualification that one should obtain to participate actively in the global world. One of the biggest responsibilities of an educational institute is to prepare the students in such a way that helps them participate actively in all of the political, social, and economic matters of the nation. Reference [12] shows one of the important factors to do so is by learning a language and especially learning the skills of that language that includes listening, reading, writing, and speaking for the interaction with the people worldwide (Ünal \& İlhan, 2017). Nevertheless, the way English as a language is taught and dealt in different educational institutes of Pakistan is not up to the mark. There are many public schools, which teach English only as a subject, and hence less time and attention is paid. The private educational institutes on the other hand do not have well qualified English language teachers and hence it directly affects the learning of the language by the students. There are many other reasons like utilization of inappropriate curriculum that does not cater to the learning needs of the students, 
under-qualified teachers for teaching English as a subject and language, fewer opportunities provided by the institutes for practicing the language, and many more.

Looking into the problem of language errors made by the students at university level, it is the first and foremost responsibility of the educational institutes to utilize appropriate language acquisition approaches which should not involve direct instruction to teach language rules but should utilize practical approaches to provide students with the opportunity of practicing language rules. This could be achieved by developing certain writing and reading clubs within the university where experts and students who are good with the language should work together as a team and help students struggling with language by providing them different opportunities of reading and writing through different competitions and other reward-based activities. Students should be encouraged for handwritten assignments instead of using electronic devices which have inbuilt automated grammar and spelling checker. Such electronic devices automatically correct the mistakes and hence students do not improve their language errors and commit the same language-based errors repeatedly.

Language workshops can also help students improve their errors through practice and activities conducted in the session followed by one-to-one meetings with the participants for a detailed feedback and observation of their improvement graph. Teachers can also play an important role in helping the students by pinpointing the mistakes made by them and then making them recognize and rectify the pinpointed mistakes themselves. The teacher should then check the mistakes corrected by the students and should provide them with feedback for further improvement. The students should use online forums like MOOCS, Coursera, different language learning applications, and online game-based language learning websites where they can practice different language skills like vocabulary, grammar, sentence structure etc.

\section{Conclusions}

Universities offering English remedial classes to the undergraduate students fail to target the root language problems faced by students. Bombarding new vocabulary each day in the remedial classes, teaching grammar rules and asking students to cram them, not providing detailed feedback about the errors made by students, and not giving them enough language practicing opportunities result in no improvement in language acquisition. A study conducted by Sahito et al., [8] at the University of Sindh explored that $90 \%$ of the students were not satisfied with the administration of remedial classes and demanded better facilities like multi-media, language laboratory, computers, and better audio, video resources to facilitate fast and better acquisition of language. Remedial classes according to Al Othman and Shuqair [1] are in fact "a quest in vain" to improve the language skills of the students. Any language remedial program offered at any university level has no effect on improving or increasing the language skills of the students.

Reference [5] shows that corrective feedback which includes "explicit correction, clarification request, recast, elicitation and paralinguistic signal" should be incorporated in the remedial classes by the teachers for increasing the language proficiency of the students. Working on the errors that each student makes and working on it with them can help these students to improve these errors. Furthermore, in person detailed feedback, more opportunities to practice in these remedial classes can also make a significant difference in the students' learning.

Based on the findings of this research study, universities should design their remedial English program so that it incorporates the eleven broad categories of errors that students tend to make. This will help students work on their weak areas and improve them. Eight semesters are a long time to work on one's errors and make using English more or less error free. Remedial English programs must be purpose-based with a clear outlook on positive expectations.

\section{REFERENCES}

[1] Al Othman, F. H. M. and Shuqair, K. M. Effectiveness of the Remedial Courses on Improving EFL/ESL Students' Performance at University Level in the Arab World. International Journal of Higher Education, 2(3), 132-138, 2013

[2] Khan, A. A. Error Analysis and Second Language Acquisition. Theory and Practice in Language Studies, 2(5), 1027-1032, 2012

[3] Kotsyuk, L. M. English Language Error Analysis of the Written Texts Produced by Ukrainian Learners: Data Collection. Cognitive Studies |Études Cognitives, 15, 389395,2015

[4] Kraichoke, C. (2017). Error Analysis: A Case Study on Non-Native English Speaking College Applicants' Electronic Mail Communications. Theses and Dissertations, $1-53,2017$

[5] Maawa, P. K. L. and Ortega-Dela Cruz, R. Remedial and Corrective Feedback Strategies for Improving Students' English Language Proficiency. International Journal of Language Education, 3(1), 1-11, 2019

[6] Mulligan, M. Error analysis of written and spoken English: practical suggestions. Revista de Lenguas Para Fines Específicos, 8(0), 401-412, 2001

[7] Presada, D. and Badea, M. The effectiveness of error 
analysis in translation classes. A pilot study. Porta Linguarum, 22, 49-59, 2014

[8] Sahito, Z., Siddiqui, A., Khawaja, M., Shaheen, A., Saeed, H and Laghari, S. H. Teaching of Remedial English and the Problems of the Students: A Case of University of Sindh, Jamshoro, Sindh, Pakistan. World Journal of English Language, 7(1), 2017

[9] Salih, Nada A. Ridha. The Effect of EFL Learners' Mother Tongue on their Writings in English: An Error Analysis Study. Journal of the College of Arts. University of Basrah 60, 22-45. 2012

[10] Sharma, D. S. and Tripathi, P. S. Error Analysis for English
Language Teaching at Primary Level. Smart Moves Journal Ijellh, 6(9), 376-382, 2018

[11] Schillinger, B. B. Error analysis : beyond the basic writer. Iowa State University Capstones, Theses and Dissertations, 1981

[12] Ünal, M and İlhan, E. A Case Study on the Problems and Suggestions in Foreign Language Teaching and Learning at Higher Education. Journal of Education and Training Studies. 5(6), 64-70, 2017

[13] Wolff, D. Integrating language and content in the language classroom: Are transfer of knowledge and of language ensured? Open Edition Journals, asp. 1154, 35-46, 2003 